\title{
Hyperventilation and circadian rhythm of the electrical stability of rat myocardium
}

\author{
This article was published in the following Dove Press journal: \\ ChronoPhysiology and Therapy \\ 29 August 2013 \\ Number of times this article has been viewed
}

\author{
Pavol Svorc ${ }^{1,2}$ \\ Alexander Marossy' \\ Pavol Svorc Jr ${ }^{2}$ \\ 'Department of Physiology, Medical \\ Faculty, Safarik University, Kosice, \\ Slovak Republic; ${ }^{2}$ Department of \\ Physiology, Medical Faculty, Ostrava \\ University, Ostrava, Czech Republic
}

Correspondence: Pavol Svorc Department of Physiology, Medical Faculty, Safarik University, tr SNP I, 0400 I Kosice, Slovak Republic

Tel +42I 556423763

Fax +42I 556423763

Email pavol.svorc@upjs.sk
Objective: Respiratory alkalosis is an extremely common and complicated problem affecting virtually every organ system where the etiologies may be related to pulmonary or cardiovascular disorders. However, there are only few works describing daytime experiments or synchronization of animals to the external environmental periodicity. The aim of the study is to describe the circadian rhythm of the electrical stability of the heart under hyperventilatory conditions.

Methods: Circadian rhythms of the electrical stability of the heart, measured by ventricular arrhythmia threshold ([VAT] measurement in 3 hour intervals), were followed during normal artificial ventilation ( 40 breaths/minute, tidal volume $=1 \mathrm{~mL} / 100 \mathrm{~g} ; \mathrm{n}=17$ ) and hyperventilation ( 80 breaths $/$ minute, tidal volume $=2 \mathrm{~mL} / 100 \mathrm{~g} ; \mathrm{n}=7)$ in pentobarbital $(40 \mathrm{mg} / \mathrm{kg}$ administered intraperitoneally) anesthetized female Wistar rats, after 4 week adaptation on the light/ dark regime of 12 hour light/ 12 hour dark (40\%-60\% humidity, room temperature of $24^{\circ} \mathrm{C}$ in cages, two animals/cage with access to food and water ad libitum), with the dark period from $18.00 \mathrm{~h}$ to $06.00 \mathrm{~h}$ for 4 weeks.

Results: The 24 hour course of the VAT showed the highest susceptibility of the rat ventricular myocardium to arrhythmias between $12.00 \mathrm{~h}$ and $15.00 \mathrm{~h}$, and highest resistance between $19.20 \mathrm{~h}$ and $00.28 \mathrm{~h}$ (acrophase $-338^{\circ}$ in time at $22.53 \mathrm{~h}$ with confidence intervals $-2,880^{\circ}$ to $-70^{\circ}$ ), under normoxic conditions. Mesor was $2.59 \pm 0.53 \mathrm{~mA}$ and amplitude $0.33 \pm 0.11 \mathrm{~mA}$. Hyperventilation increased the VAT at each interval of the measurement, but did not change the character of its circadian rhythm. Acrophase was on $-40^{\circ}(02.40 \mathrm{~h})$, mesor was increased (2.91 mA), and amplitude was decreased $(0.13 \mathrm{~mA})$.

Conclusion: Although hyperventilation insignificantly increased the electrical stability of the heart compared to values of electrical stability of the heart during normal pulmonary ventilation during the whole 24 hour period, the results show that hyperventilation probably only modulates, but not disturbs, the circadian rhythm of the electrical stability of the heart in pentobarbital anaesthetized female Wistar rats.

Keywords: circadian rhythm, myocardial vulnerability, hyperventilation, rat

\section{Introduction}

Disorders of pulmonary ventilation are considered to be proarrhythmogenic. Pulmonary hypoventilation induced systemic asphyxia has harmful effects on the heart and produces substrates that contribute to the development and onset of ventricular arrhythmias. ${ }^{1,2}$ In addition, respiratory alkalosis is an extremely common and complicated problem affecting virtually every organ system in the body, the etiology of which may be related to pulmonary or extrapulmonary factors. There are many cardiac effects of pulmonary hyperventilation induced respiratory alkalosis including 
tachycardia, heart rhythm disorders, ${ }^{3}$ and supraventricular tachycardia caused by altered atrioventricular nodal conduction. ${ }^{4}$

Knowledge regarding circadian variations of the electrophysiological properties of the heart may help to more precisely evaluate the risk of ventricular arrhythmia incidence. The evidence in the literature regarding circadian patterns in arrhythmias is complicated by the fact that nearly all of the studies are confounded by a variety of factors independent of the intrinsic arrhythmogenic activity. ${ }^{5}$

Using a rat model, we examined the circadian rhythm of myocardial vulnerability and found it to be highest between $12.00 \mathrm{~h}$ and $15.00 \mathrm{~h}$ and lowest between $00.00 \mathrm{~h}$ and $03.00 \mathrm{~h}$ in normally ventilated rats anesthetized using pentobarbitol. ${ }^{1,2}$ However, the effects of hyperventilation on circadian fluctuations of the electrical stability of the heart have not been examined. The aim of the present study was to test the hypothesis that hyperventilation modulates the circadian rhythm of myocardial vulnerability to ventricular arrhythmias in an in vivo rat model involving animals anesthetized with pentobarbital.

\section{Methods}

\section{Ethics approval}

The present study was performed in accordance with the Guide for the Care and Use of Laboratory Animals, published by the United States National Institutes of Health (NIH publication number 85-23, revised 1996). The study protocol was also approved by the Ethics Committee of the Medical Faculty of Safarik University (Kosice, Slovak Republic) (permission number 2/05).

\section{Adaptation and anesthesia of animals}

The circadian fluctuation of the electrical stability of the heart, measured according to ventricular arrhythmia threshold (VAT), was examined during normal artificial ventilation and hyperventilation in female Wistar rats anaesthetized with pentobarbital (40 $\mathrm{mg} / \mathrm{kg}$ administered intraperitoneally) that had been adapted to a daily light/dark cycle of 12 hour light/12 hour dark (dark period from $18.00 \mathrm{~h}$ to $06.00 \mathrm{~h}$ ) for 4 weeks. Rats were housed two animals per cage at a temperature of $24^{\circ} \mathrm{C}$ and humidity of $40 \%$ to $60 \%$, with ad libitum access to food and water.

Anesthesia was maintained at a level at which painful stimuli and surgery did not evoke noticeable motor or cardiovascular responses. On completion of the experiments, the animals were euthanized by cardiac administration of an overdose of pentobarbital.

\section{Experimental protocol}

Animals were randomly divided into two groups. Group 1 was ventilated using normal parameters of artificial ventilation (40 breaths $/$ minute, tidal volume $=1 \mathrm{~mL} / 100 \mathrm{~g}$ body weight; $\mathrm{n}=17$ ) and group 2 was hyperventilated ( 80 breaths $/$ minute, tidal volume $=2 \mathrm{~mL} / 100 \mathrm{~g} ; \mathrm{n}=7$ ) based on validated methods of artificial controlled ventilation using room air in pentobarbital anaesthetized rats that led to the preservation of normal acid-base balance. The effects of artificial ventilation on respiration were monitored by analysis of $\mathrm{pH}$, partial pressure of $\mathrm{CO}_{2}$, and partial pressure of $\mathrm{O}_{2}$. The changes in blood gases and $\mathrm{pH}$ were measured in blood samples drawn from the femoral artery (Table 1).

VAT measurements were performed at 3 hour intervals at approximately $09.00 \mathrm{~h}, 12.00 \mathrm{~h}, 15.00 \mathrm{~h}, 18.00 \mathrm{~h}, 21.00 \mathrm{~h}$, $00.00 \mathrm{~h}, 03.00 \mathrm{~h}, 06.00 \mathrm{~h}$, and $09.00 \mathrm{~h}$, while the rat was supine. The VAT measurements were performed at a temperature equivalent to the rectal temperature of the rat measured before administration of the anesthetic agent. The body temperature of the animals was maintained using an infrared heat lamp.

\section{Measurement of VAT}

The VAT was estimated as the minimal amount of electrical current (in $\mathrm{mA}$ ) required to elicit a ventricular arrhythmia. It was measured directly by electrical stimulation of the heart during the open chest experiments. The stimulating electrodes ( $1 \mathrm{~mm}$ in diameter; $5 \mathrm{~mm}$ interelectrode distance) were fixed at the base of the right ventricle while the animal was supine. Cardiac stimulation (using rectangular pulses with a frequency of $30 \mathrm{~Hz}$, impulse length of $10 \mathrm{~ms}$, and duration of stimulation of $400 \mathrm{~ms}$ ) was triggered by the initial pulse of the $\mathrm{R}$ wave. The current intensity was progressively increased in increments of $0.2 \mathrm{~mA}$ until ventricular arrhythmias occurred. The parameters used for stimulation were chosen so that at least one impulse was applied during the vulnerable period, provided the duration of the stimulation covered a minimum of two to three heart cycles. The ventricular arrhythmias were of a mixed type, with spontaneous mutual transitions among

Table I Blood gas values and $\mathrm{pH}$ in rats exposed to normal ventilation and hyperventilation compared with data from Hess et $\mathrm{al}^{6}$

\begin{tabular}{lccc}
\hline & Literature & Normoventilation & Hyperventilation \\
\hline $\mathrm{pH}$ & $7.47 \pm 0.04$ & $7.51 \pm 0.05$ & $7.58 \pm 0.06$ \\
$\mathrm{PCO}_{2}(\mathrm{kPa})$ & $4 \pm 0.6$ & $2.9 \pm 0.5$ & $1.7 \pm 0.3$ \\
$\mathrm{PO}_{2}(\mathrm{kPa})$ & $13.9 \pm 1.6$ & $12.7 \pm 3.1$ & $15.3 \pm 3.7$ \\
\hline
\end{tabular}

Notes: Values are presented as mean \pm standard deviation. Values are for an entire 24 hour period regardless of the light/dark cycle of the rat.

Abbreviations: $\mathrm{pCO}_{2}$, partial pressure of $\mathrm{CO}_{2} ; \mathrm{PO}_{2}$, partial pressure of $\mathrm{O}_{2}$. 
ventricular fibrillation, ventricular tachycardia, and flutter, and were comparable between the two groups.

\section{Statistical analyses}

Results are expressed as mean \pm standard deviation. The basic circadian parameters were assessed using single and population mean cosinor tests. The data were obtained from trials that were conducted over the seasons because circannual variation can also occur in the parameters that were examined.

\section{Study limitations}

The absence of data regarding VAT parameters in nonanesthetized animals as well as the light/dark dependence of VAT parameters was a limitation of the present study. These data are also lacking in the literature. In addition, there was a relatively large dispersion of the values measured in the present study. VAT values revealed intra- and interindividual variability, which is an issue inherent to in vivo studies. The discrepancies can be explained by spontaneous, unpredictable alterations in the electrophysiological properties of the heart induced by anesthesia, or hormonal and homeostatic reflexes in the animals.

\section{Results}

In the normoxic group, the acrophase of the significant VAT circadian rhythm was $-338^{\circ}$ (95\% confidence interval [CI]: $-288^{\circ}$ to $\left.-7^{\circ}\right)$ at $22.53 \mathrm{~h}$ ( $95 \% \mathrm{CI}: 19.20 \mathrm{~h}$ to $00.28 \mathrm{~h}$ ), with mesor $2.59 \pm 0.53 \mathrm{~mA}$ and amplitude $0.33 \pm 0.11 \mathrm{~mA}$.

In the hyperventilatory group, VAT was insignificantly increased at each interval of the measurement, but the character of the circadian rhythm was not altered. There was no significant change in the hyperventilatory 24 hour rhythm of the VAT, although acrophase was shifted to $-40^{\circ}(02.40 \mathrm{~h})$, mesor was increased $(2.91 \mathrm{~mA})$, and amplitude was decreased (0.13 mA) (Figure 1).

\section{Discussion}

Hyperventilation does not disturb, but likely only modifies, the circadian rhythm of the electrical stability of the heart. Hyperventilation decreases the amplitude, increases the mesor, and shifts the acrophase of the circadian rhythm of VAT compared with the circadian rhythm during normal ventilation.

The role of the autonomic nervous system (ANS) should be considered because the ANS is one of the factors directly controlling the circadian rhythm of the electrical stability of the heart. Circadian rhythms in ANS activity are well known and represent triggers of cardiac arrhythmias. ${ }^{5,7,8}$ However, there is no direct evidence regarding the effects of hyperventilation on the circadian rhythm of QT dispersion. We can hypothesize that if there is circadian variation in QT interval dispersion, and QT dispersion is not altered by ventilatory interventions (eg, during the Valsalva maneuver in healthy young adult men), ${ }^{9}$ then hyperventilation likely does not influence ANS activity. Therefore, circadian variation in the ANS does have to alter the circadian rhythm of the electrical stability of the heart.

The modification of the circadian rhythm of myocardial vulnerability may be the result of altered ion distribution during hyperventilation. To date, there have been no studies investigating the effects of hyperventilation on the

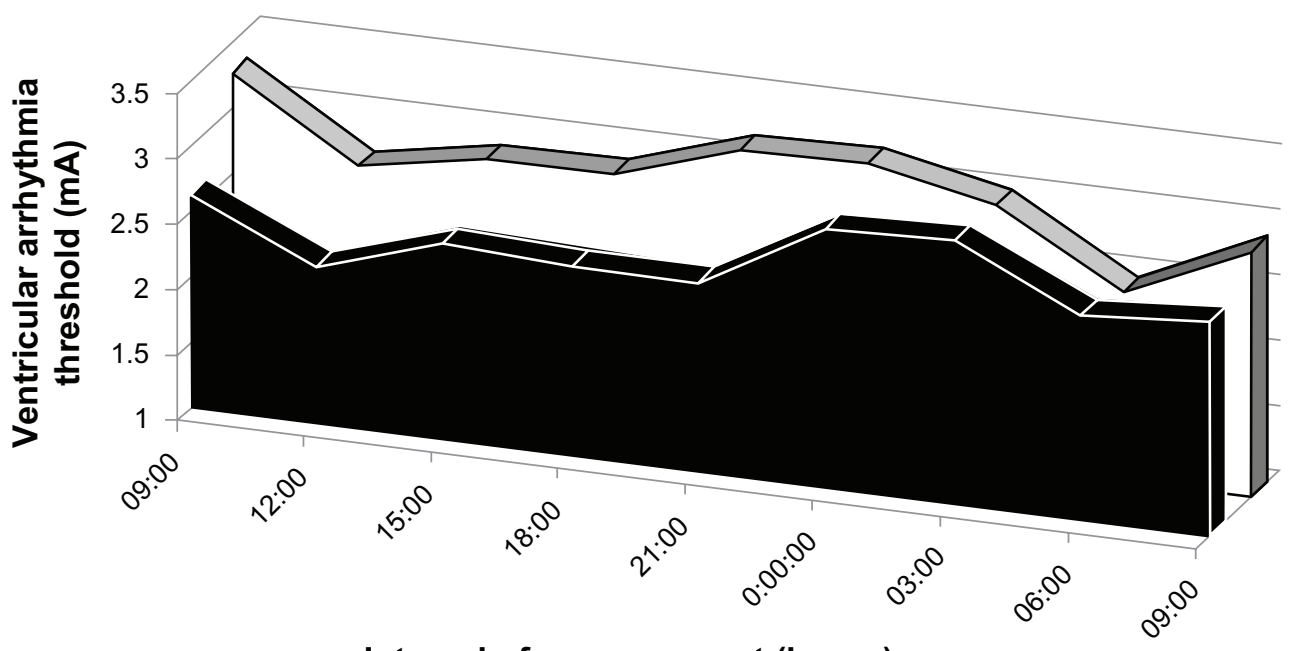

Interval of measurement (hours)

Figure I Circadian rhythms of the ventricular arrhythmia threshold during normal ventilation (black) and hyperventilation (white). Notes: The values are presented as mean \pm standard deviation. The dark period of the light cycle was from $18.00 \mathrm{~h}$ to $06.00 \mathrm{~h}$. 
circadian rhythm of ion concentrations in the myocardium. If the electrophysiological properties of the myocardium are determined primarily by ion distributions and currents, the effects of hyperventilation on circadian rhythm may be mediated through changes in these factors.

The dispersion of the refractory period duration (QT interval) depends mainly on the intracellular $\mathrm{K}^{+}$concentration, ${ }^{10}$ but also it may be the result of action of ion currents as $\mathrm{Ca}^{2+}$, $\mathrm{Na}^{+}$, and $\mathrm{Cl}^{-}$currents and inward rectifying $\mathrm{K}^{+}$current. ${ }^{11}$ It has been proved that a direct correlation between the occurrence of ventricular arrhythmias and serum $\mathrm{K}^{+}$exists, where at higher $\mathrm{K}^{+}$levels, the incidence of ventricular arrhythmias is decreased. ${ }^{12,13}$ Also in circadian dependence, the maximal $\mathrm{K}^{+}$concentration coincides with the minimal myocardial vulnerability to the ventricular arrhythmias in rats. ${ }^{14}$ This probably means that the circadian pacemaker controlling the rhythm of serum $\mathrm{K}^{+}$levels plays a key role also in the control of VAT circadian rhythms in rats under normal ventilation conditions. The increase in the electrical stability of the heart and the preservation of the circadian rhythm may be due to the increase of $\mathrm{K}^{+}$serum concentration over the entire 24 hour period during hyperventilation. Arrhythmias originating from disorders of impulse production and conduction depend mainly on action potential amplitude, reflecting the role of $\mathrm{Na}^{+}$channels. ${ }^{10,15}$ Significantly higher $\mathrm{Na}^{+}$levels occur in the dark (active) period of the day in the rat. ${ }^{14}$ Such fluctuations in $\mathrm{Na}^{+}$levels may also contribute to alterations in the myocardial vulnerability to the previously mentioned types of arrhythmias. Hyperventilation induced systemic alkalosis does not influence the circadian rhythm of ion concentrations, but likely increases serum $\mathrm{K}^{+}$and $\mathrm{Na}^{+}$levels and increases myocardial resistance against ectopic stimuli.

\section{Conclusion}

Hyperventilation insignificantly increased the electrical stability of the heart in each interval of the measurement during the 24 hour period compared to values during normal pulmonary ventilation. Because the myocardial vulnerability was lower during the dark (active) than during the light (nonactive) part of the day, it refers to the fact that hyperventilation probably modulates but not disturbs the circadian rhythm of the myocardial vulnerability in pentobarbital anaesthetized female Wistar rats. These results affirm that light/dark cycle related differences are not merely transient or procedure dependent, but are a systematic response caused by distinct neurohumoral regulation during the light and dark periods of day, and also occur under pentobarbital anesthesia.

\section{Acknowledgment}

This work was supported by VEGA grant 1/0423/11.

\section{Disclosure}

The authors report no conflict of interest in this work.

\section{References}

1. Svorc P, Wilk P, Murár J, et al. Circadian rhythm of the ventricular fibrillation threshold in female Wistar rats. Physiol Res. 1994;43(6): 355-358.

2. Svorc P, Podlubny I, Kujanik S, Bracokova I. 24 h rhythm of the ventricular fibrillation threshold during normal and hypoventilation in female Wistar rats. Chronobiol Int. 1997;14(4):363-370.

3. Foster GT, Vaziri ND, Sassoon CS. Respiratory alkalosis. Respir Care. 2001;46(4):384-391.

4. Chen CC, Chen SA, Tai CT, Kuo TBJ, Chang MS, Prystowsky EN. Hyperventilation facilitates induction of supraventricular tachycardia: a novel method and the possible mechanism. JCardiovasc Electrophysiol. 2001;12(11):1242-1246.

5. Portaluppi F, Hermida RC. Circadian thythms in cardiac arrhythmias and opportunities for their chronotherapy. Adv Drug Del Rev. 2007;59(9-10):940-951.

6. Hess L, Dvoracek I, Svobodnik L. Anestézie laboratoních zviŕat. [Anaesthesia of the lab animals]. Avicenum, Prague, 1984;158.

7. Bissinger A, Markuszewski L, Rosiak M. Value and circadian variations of QT dispersion in patients with diabetes mellitus and coronary artery disease. Pol Merkury Lekarski. 2008;24(140):90-94. Polish.

8. Hansen S, Rasmussen V, Torp-Pedersen C, Jemsen GB. QT intervals and QT dispersion determined from a 12-lead 24-hor Holter recording in patients with coronary artery disease and patients with heart failure. Ann Noninvasive Electrocardiol. 2008;13(1):22-30.

9. Haapalahti P, Makijavri M, Montonen J, et al. Effects of cardiovascular autonomic function tests on QT dispersion in the 12-lead electrocardiogram of healthy patients. J Electrocardiol. 2000;33(4):321-327.

10. Froldi G, Pandolfo L, Chinellato A, Ragazzi E, Caparrota L, Fassina G. Protection of atrial function in hypoxia by high potassium concentration. Gen Pharmacol. 1994;25(3):401-407.

11. Amitzur G, Schoels W, Visokovsky A, et al. Role of sodium channels in ventricular fibrillation: A study in nonischemic isolated hearts. J Cardiovasc Pharmacol. 2000;36(6):785-793.

12. Curtis, MJ, Johnston KM, Walker MJA. Arrhythmias and serum potassium during myocardial ischaemia. Medical Science. 1985;13[8]688-689.

13. Winslow E, Walker G, Mason R. Antiarrhythmic effects of selective $\beta_{1}-$ and $\beta_{2}-$ and nonselective $\beta$-adrenoreceptor blockade in normokalaemic and dietary-induced hypokalaemic rats. $J$ Cardiovasc Pharmacol. 1989;14(5):673-680.

14. Granda TG, Velasco A, Cachero TG. Circadian rhythms of plasma concentrations of $\mathrm{Na}^{+}$and $\mathrm{K}^{+}$and their urinary excretion in normal and diabetic rats. Biol Rhythm Res. 1996;27(1):31-42.

15. Carmeliet E. Electrophysiology of cardiac arrhythmias. Recent developments. Revista de Farmacologia Clinicay Experimental. 1988;5(2):121-122. ISSN: 0213-0157. 
ChronoPhysiology and Therapy

\section{Publish your work in this journal}

ChronoPhysiology and Therapy is an international, peer-reviewed, open access journal focusing on research into the cyclic variations and rhythmicity in physiological processes in the body and the research and development and optimal timing of administration of therapeutic targets to achieve improved outcomes and quality of life for the patient. The

management system is completely online and includes a very quick and fair peer-review system. Visit http://www.dovepress.com/ testimonials.php to read real quotes from published authors.

Submit your manuscript here: http://www.dovepress.com/chronophysiology-and-therapy-journal 